\title{
TRABALHO DOS PROFESSORES E CONFLITOS NA ESCOLA: UMA ABORDAGEM PEDAGÓGICA*
}

\author{
WORK TEACHERS AND CONFLICTS AT SCHOOL: \\ A PEDAGOGICAL APPROACH
}

\author{
TRABAJO DE LOS PROFESORES Y CONFLICTOS EN LA ESCUELA: \\ UN ABORDAJE PEDAGÓGICO
}

Liliana Soares Ferreira Doutora em Educação; professora do programa de pós-graduação em Educação da Universidade Federal de Santa Maria - RS

\begin{abstract}
RESUMO: Parte-se do suposto de que, inevitavelmente, ao produzirem seu trabalho na escola, os professores vivenciarão conflitos consigo, com os outros professores, com os estudantes e com os demais sujeitos que participam desse cotidiano. Nesse sentido, este artigo objetiva apresentar compreensões acerca dos conflitos no trabalho de professores na escola. Os argumentos apresentados foram elaborados com base em estudo que considerou, após entrevista oral e transcrição, a análise de discursos de oitenta professores de escolas públicas no Rio Grande do Sul, além de pesquisa bibliográfica e sistematização (esta entendida como produção de sentidos sobre o tema). Na argumentação, enfatiza-se a necessidade de análise nas relações trabalho e emprego dos professores, a convivência com estudantes e demais professores, como fontes de conflito. Estes são processos enfrentados pelos professores, muitas vezes, caracterizados como processos negativos. Porém, se pode vê-los também como oportunidades para se repensar o trabalho dos professores e a escola.
\end{abstract}

PALAVRAS-CHAVE: Trabalho pedagógico. Conflitos. Escola.

ABSTRACT: It is supposed that, inevitably, at producing their work at school, the teachers will have to face conflicts with themselves, with other teachers, with students and with other person that participate of that daily routine. In this respect, this article presents insights about the conflicts in the work of teachers at school. The presented arguments have been based on the study which considered, after oral interview and transcription, the analysis of discourses of eighty teachers of public schools in the State of Rio Grande do Sul, besides systematic literature search (understood as production of meaning on the subject). In the argument, it is emphasized the need for analysis, in the teachers work and employment relationship, the living with other students and teachers as sources of conflict. These are processes faced by teachers, often characterized as negative processes. However, they can also been seen as opportunities to think over the work of teachers and the school.

KEYWORDS: Pedagogical work. Conflicts. School.

RESUMEN: Se supone que, inevitablemente, los maestros al presentar sus trabajos en la escuela, experimentan, por ejemplo, los conflictos entre sí como entre otros profesores, estudiantes y otros sujetos que participan en esta rutina diaria. Entonces, este artículo objetiva presentar reflexiones acerca de los conflictos en las actividades de los profesores en la escuela. Los argumentos expuestos fueron elaborados con base en estudio que se lleva en consideración, después de la entrevista oral y transcripción, el análisis de discursos de ochenta profesores de escuelas públicas en el Rio Grande do Sul, investigación bibliográfica y sistematización, entendida como producción de sentidos sobre el tema. En la argumentación, se enfatiza la necesidad de análisis en las relaciones de trabajo y empleo de los profesores; la convivencia entre estudiantes y profesores, como fuentes de conflictos. Estos son procesos enfrentados por los docentes, muchas veces, caracterizados como procesos negativos. Sin embargo, se puede verlos también como oportunidades para repensar el trabajo de los profesores y de la escuela.

PALABRAS CLAVE: Trabajo pedagógico. Conflictos. Escuela.

\footnotetext{
* Artigo recebido em
}

Aprovado em

Cad. Pes., São Luís, v. 21, n. 1, jan./abr. 2014. 


\section{1 | Introdução}

Nesse artigo, intenciona-se apresentar abordagens sobre duas noções, aparentemente, antitéticas: o trabalho, entendido como possibilidade de produção da sobrevivência, da historicidade e, portanto, autoprodução humana; e os conflitos que, senso comum, são vistos como dificultadores da (com)vivência. Do mesmo modo, entende-se que, pelo trabalho, o ser humano se autoproduz e se desenvolve livre. Esta liberdade é relacionada ao desenvolvimento humano, "como ser prático, transformador ou criador, isto é, está vinculado ao processo de produção de um mundo humano ou humanizado, que transcende o mundo dado, natural, bem como ao processo de autoprodução do ser humano que constitui precisamente a sua história" SÁNCHEZ VÁZQUEZ, 1977, p. 129-130). Essa aproximação exige que se percorra um caminho conceitual, partindo da noção de trabalho, em especial, de trabalho dos professores, desde noções de conflito no trabalho desses profissionais para chegar a inter-relacioná-los, sistematizando possibilidades de compreendê-los imersos em um espaço e um tempo institucionais específicos, a escola. O trabaIho dos professores é, inerentemente, trabalho pedagógico. Trabalho pedagógico, que, se compreende, como sendo o trabalho dos professores na escola, portanto, práxis pedagógica que é a essência do trabalho profissional dos professores e, nessa perspectiva, torna-se científica, por isso, metódica, sistemática, hermeneuticamente elaborada e teoricamente sustentada. Pode-se dizer uma práxis pedagógica, então, uma práxis social, porque "[...] socialmente elaborada e organizada conforme intencionalidades, conhecimentos" (FERREIRA, 2008, p.184). Desse modo, são apresentados argumentos que vão do conceitual ao contextual, tendo o trabalho como noção que se assume como interface possibilitadora da análise.

Parte-se do suposto de que, inevitavelmente, ao produzirem seu trabalho na escola, os professores vivenciarão conflitos consigo, com os outros professores, com os estudantes e com os demais sujeitos que participam desse cotidiano. O importante é, antes de analisar o conflito em si, analisar como é tratado:

[...] encarado como negativo e destruidor, o conflito é necessário à vida, inerente e constitutivo tanto da vida psíquica como da dinâmica social. Sua ausência indica apatia, total submissão e, no limite, remete à morte. Sua não explicitação pode levar à violência. Mesmo que se possa confundir com ela, conflito não é sinônimo de violência. Violentos podem ser os meios de resolução ou os atos que tentam expressar um conflito que não pode ser formulado, explicitado (GALVÃO, 2004, p. 15).

A análise desses conflitos e dos modos de enfrentá-los, neste artigo, é pedagógica, na medida em que produz um conhecimento dos conflitos, do ser humano, de como se convive com eles e de como se aprende a partir dessa convivência. Pedagógica, então, no sentido de ser uma meta-aprendizagem: dos conflitos e de como lidar com eles, sendo professores na escola.

Como campo empírico, foram considerados os estudos realizados sobre o trabalho dos professores. Nesses processos, entrevistando oitenta professores na Região Central do Rio Grande do Sul, entre 2008 e 2010, foram constatadas manifestações de diversas modalidades de conflitos que perturbam os professores em seu trabalho. Esses professores, mulheres e homens que atenderam a um convite para participar da pesquisa, estão inclusos na escola como servidores do Estado, em média, há dez anos, na ocasião das entrevistas. Suas idades variavam entre vinte e cinco e cinquenta anos. Todos eram licenciados em suas áreas do conhecimento e trabalhavam com o Ensino Fundamental. As entrevistas sobre trabalho e conflitos na escola integraram um estudo com o objetivo de analisar como os professores discursavam sentidos sobre seu trabalho e sobre si próprios como trabalhadores e, nesse contexto, os conflitos que enfrentavam. Considerou-se como base que esses sujeitos trabalham em escolas públicas estaduais, sendo partícipes na implementação e (re)contextualização das políticas educacionais e nos processos 
de gestão nos dois últimos governos estaduais, com destaque o discurso sobre democratização da gestão, o "enturmamento" (aumento da quantidade de estudantes por turma), as paulatinas perdas salariais e o aumento da exigência de estudos continuados em acordo com o discurso ideológico sobre a defesa da necessidade de desenvolvimento de competências e manutenção da empregabilidade, fatores que acirraram os graus de intensificação, precarização e fragmentação do trabalho dos professores. Em decorrência dessas situações, produziram-se conflitos, vivenciados cotidianamente e, às vezes, por longos períodos de tempo, que acabam naturalizados, sem que sejam amenizados ou mesmo analisados, o que, também, contribui para o aumento do conflito. Gera-se uma espécie de mal-estar que, em continuidade, pode produzir comportamentos dissonantes, tais como rusgas entre os sujeitos da escola, ausência no processo de produção do conhecimento e até mesmo resistência passiva, sob a forma de estar na escola, mas dela não participar. Tal prolongamento de um conflito é causador de sofrimento, posto ser resultante de certo estado de intranquilidade, a ponto de adoecer ou mesmo tornar insuportável a profissão.

Considerou-se, ainda, que o cotidiano dos professores é tão intenso, exige investimentos de elementos subjetivos tão diferentes, às vezes, até contraditórios entre si, porque é pautado por convivências. Nessas convivências, se estabelece um acirramento de conflitos, gerando-se dilemas. Entende-se que dilemas se configuram em um estágio além dos conflitos e são vivências "[...] subjectivas (não as situações externas), os conflitos interiores, cognitivos e práticos, ocorridos em contextos profissionais e em relação aos quais o professor equaciona duas ou mais alternativas (da acção e/ou valoração" (CAETANO, 1997, p. 194). Tudo isso colabora para o estabelecimento de uma percepção dos dilemas como sendo relativos às dificuldades em decidir, superar diferenças de opiniões e chegar a deliberações que amenizem as dificuldades de convivência. Em um artigo no qual sistematiza pesquisa semelhante à apresentada nesse artigo, analisando discursos de professores com o objetivo de descrever os dilemas cotidianos vivenciados por esses profissionais na escola, Caetano, de modo otimista, observa que "[...] os dilemas, como fonte de inquietação, são germe de mudança. À volta deles pode-se gerar uma dinâmica individual e colectiva potenciadora do desenvolvimento do profissional e da profissão" (CAETANO, 1997, p. 218). Reitera-se que se está priorizando nesse artigo uma abordagem sobre conflitos, entendendo que os dilemas seriam uma fase posterior, mais acirrada dos conflitos. Para tanto, tem-se como base a perspectiva de compreender que os professores são sujeitos do desejo. A realização desse desejo é demandante e estrutural. Não obstante, quando vivenciam sua inserção em um trabalho que, de algum modo, se opõe ao desejo, podem vir a sofrer, ou seja, vivenciar conflitos de toda ordem. Portanto, sujeito compreendido como ser constituído a partir de [...] um conjunto de vivências afetivas nas várias situações da vida, suas relações familiares, sociais e no trabalho" (BERTÃO; HASHIMOTO, 2006, p. 141), ou seja, aquele que tem registradas suas experiências, boas ou não, e com elas acaba por elaborar sua história de vida, sua subjetividade e sua singularidade (BERTÃO; HASHIMOTO, 2006, p. 141).

Tendo por base esse preâmbulo, esse artigo foi organizado a partir de uma metodologia escolhida em acordo com um objetivo: analisar e compreender nos discursos dos professores entrevistados ${ }^{1}$ os conflitos descritos como presentes no trabalho que realizam na escola. Para tanto, estabeleceu-se uma sequência na escrita: reflexão sobre os argumentos-base; pesquisa bibliográfica para aprofundamento das noções que fundamentam os argumentos; escrita inicial, com sistematização, organização e revisão da versão final. Os argumentos apresentados inicialmente, então, se ampliaram e exigiram a inclusão, por exemplo, de emprego, de sujeito do desejo, com os quais se argumentará ao longo do texto. Considerou-se, ainda, as interações com os estudantes, além da (com)vivência na profissão como aspecto que também gerou conflitos, segundo os discursos. É sobre esses elementos que se argumenta nas seções seguintes.

${ }^{1}$ Quando citados os discursos, esses sujeitos são designados com nomes fictícios, por eles escolhidos, durante a entrevista.

Cad. Pes., São Luís, v. 21, n. 1, jan./abr. 2014. 


\section{2 | O conflito de trabalhar como professores na contemporaneidade e a iminência da ruptura}

Assim como optar pelo trabalho como professor é o manifesto de um desejo, também os conflitos o são. Por desejo, entende-se o elemento gerador de uma escolha, e escolhas não são gratuitas, estão determinadas no âmbito do inconsciente, o que significa dizer que as relações e os investimentos sociais visam a atender a um vazio estruturante da condição do sujeito. Explica-se com as afirmações de Garcia-Roza (1991, p. 145) que, com base em Freud, caracteriza o desejo como "[...] impulso para reproduzir alucinatoriamente uma satisfação original, isto é, um retorno a algo que já não é mais, a um objeto perdido cuja presença é marcada pela falta [...] o que caracteriza o desejo é a presença de uma ausência". Se o sujeito visa a atender o seu desejo, irá necessariamente buscar um lugar para se representar que revele os meios e modos julgados por ele compatíveis com sua singularidade. Ser bem-sucedido nessa busca decorre da relação entre a condição subjetiva e o meio no qual se inseriu, ou, em outras palavras, compatibilidade entre o lugar onde se representar e o desejo. O conflito, assim, surge quando determinações externas ao sujeito: valores, crenças, institucionalizações impedem o sujeito de circular com sua palavra, com seu discurso, de modo que seu desejo não encontra possibilidades de realização. Há, então, a impossibilidade de haver o encontro de outro modo de representação que permita também a concretização do desejo. Ainda assim não leva a abdicar do desejo, apenas gera a necessidade de buscar formas de satisfação e reconhecimento. No caso dos professores, os conflitos são demasiadamente problemáticos, porque seu trabalho é com pessoas, singularmente constituídas, o que lhes exige um autocontrole nem sempre possível, mas necessário. Em outras palavras, é no trabalho que os professores, por serem professores, enfrentam conflitos, na condição natural de ser humano, mas seres humanos que lidam com seres humanos. Cabe, então, entender melhor esse espaço e tempo tão complexo que é o trabalho dos professores e as implicações do desejo.

Sabe-se que o trabalho permite ao sujeito reconhecer-se e agir como agente transformador no processo evolutivo da sociedade. Essa importância existe porque há um sujeito que busca, através de ações, ocupar um espaço e um tempo, demandado já que tende a responder do lugar onde se encontra em relação a outro (ou Outro): "Há dois outros que se devem distinguir, pelo menos dois - outro com ' $A$ ' maiúsculo e outro com 'a' minúsculo, que é o eu. O Outro, é dele que se trata na função da fala” (LACAN, 1985, p. 297). Tal questão remete à constituição subjetiva, ilustrando a alienação frente ao Outro, ou seja, o reconhecimento de si somente a partir do desejo daquele. Nas relações de trabalho, a alienação parece reeditar-se, pois as ações implicadas precisam, necessariamente, estar remetidas a outro, o que permite pensar na constituição do sujeito que, inicialmente, se efetivou também sob o desejo de outro. A alienação para Sartre é entendida como um efeito histórico real sobre os seres humanos e complementa: "Ora, na fase atual de nossa história, as forças produtivas entraram em conflito com as relações de produção, o trabalho criador é alienado, o homem não se reconhece em seu próprio produto e seu labor extenuante apresenta-se-Ihe como uma força inimiga" (SARTRE, 2002, p. 25). Diante disso, é possível pensar na importância do trabalho para a condição humana, bem como na prevalência de condições que o ser humano intenciona para se satisfazer através do seu trabalho. Isso ressalta a argumentação de que sempre haverá a dimensão do desejo implicada, pois, embora inconsciente, o desejo impera, determinando as escolhas dos sujeitos.

Mesmo que ocorram variantes em seu transcurso, o trabalho é um ato consciente que remete a uma dimensão fundamental da constituição do humano: a dimensão teleológica. Nesse sentido, o trabalho é colocado como o centro da hominização, diferenciando o ser humano dos demais animais. Enfim, através do trabalho, os seres humanos transformam-se, tornam-se seres sociais, que é a "[...] condição para sua existência [...] independentemente de todas as formas de 
sociedade, eterna necessidade natural de mediação do metabolismo entre homem e natureza e, portanto, vida humana" (ANTUNES, 2003, p. 23).

Esses aspectos, vistos em perspectiva contextual, levam a considerar que as mudanças no mundo capitalista influenciaram diretamente na configuração da escola e implicaram, sobretudo, em mudança no sistema de produção e, em decorrência, geraram desemprego estrutural; uma suposta vitória do capitalista com a queda dos governos de inspiração socialista; o desaparecimento da social-democracia clássica; o acirramento das relações de trabalho nos contextos neoliberais, exigindo que os trabalhadores trabalhem mais e recebam salários cada vez menores (ANTUNES, 2003).

Nesse contexto, a expansão do ensino e do atendimento a uma maior parcela da população se, por um lado, indicaram uma maior democratização do acesso à educação, por outro, geraram a necessidade de reconfiguração do trabalho dos professores. Produzir aula e, nela, o conhecimento, nesses últimos trinta anos, sofreu mudanças recorrentes e, hoje, não se pode imaginar a aula igual à como acontecia há poucos anos atrás. Entretanto, essa mudança, que é rápida no contexto escolar, não o é no modo de pensar e agir dos professores, gerando certo desconforto, uma sensação de inadequação, de não acompanhar o processo educacional. Trata-se de uma sensação de não reconhecimento de um lugar para se representar como sujeito. Ou seja, percebe-se que o sistema capitalista parece objetivar retirar cada vez mais do trabalhador a autoria do seu trabalho. Isto se aplica aos professores também. Nessas últimas décadas, paulatinamente, os professores perderam o status de serem responsáveis pelo planejamento de seu trabalho, tornando-se reprodutores de aulas e de um trabalho pedagógico pensado ou orientado por outros. Como exemplos dessa influência externa aos professores, cita-se a explosão dos especialistas em educação, a partir da década de 1940; os currículos tecnicistas a partir da década de 1960; os Parâmetros Curriculares Nacionais a partir da década de 1990; entre tantas outros. Gera-se, então, uma indagação: de onde se origina o reconhecimento que os professores buscam em seu trabalho, se esses trabalhadores se encontram, muitas vezes, na situação de não autoria do que produzem?

Trabalhar e perceber-se como sujeito são elaborações a partir da constante significação e ressignificação social do trabalho, da revisão das tradições, da reafirmação de práticas consagradas culturalmente que permanecem significativas, do confronto entre teorias e práticas, da análise teórica sistemática do trabalho pedagógico. Constroem-se também pelos significados que os professores atribuem a si próprios, em seus contextos escolares, com base em como se situam no mundo, suas crenças e valores, sua historicidade, sob influência "[...] de suas representações, de seus saberes, de suas angústias e anseios, do sentido que tem em sua vida o ser professor. Assim como a partir de sua rede de relações com outros professores, nas escolas, nos sindicatos e em outros agrupamentos" (PIMENTA, 1999, p. 98).

Nessa argumentação, considera-se, ainda, que, de modo geral, a literatura em educação apresenta a escola como o local de trabalho dos professores, onde podem se realizar e satisfazem-se através da produção da aula e da participação nos diferentes espaços de planejamento e ação. Porém, acredita-se que a escola, mais que o ambiente de trabalho, é o espaço do aprender a trabalhar como professores. E esta não é uma novidade, sem dúvida. Sempre foi assim na história da escola. O que acontece é que, não raramente, relega-se esta condição apenas aos estudantes, apresentando-os como os únicos que aprendem na escola. Tais características de um trabalho que exige superação em contínuo pode possibilitar o encaminhamento para conflitos também contínuos. Romper é uma espécie de violência simbólico-subjetiva contra quem rompe, pois the sugere uma mudança, uma quebra de continuidade, e responder a isso nem sempre é possível. Vivem, então, os professores, cotidianamente, a iminência de uma ruptura. Desejam reconhecimento, mas nem sempre o conseguem. O não reconhecimento gera o desejo de romper com a situação da qual não se sentem inteiramente participantes. Esse talvez seja o 
seu maior conflito no trabalho: como lidar com o desejo de romper com o trabalho? Ou, em outra versão, como evitar uma ruptura em seu trabalho? Ou ainda: como lidar com o impedimento da satisfação gerado pelas condições de emprego? Entende-se que são duas possibilidades:

a) proceder à ruptura e, decorrentemente, acontecer o enfrentamento de uma situação que o lança em novo conflito;

b) evitar o sofrimento da ruptura em nome da condição confortável e acomodada, reproduzindo a ordem, ausentando-se, mesmo estando presente, de seu trabalho, omitindo-se, o que não exime de outro conflito, mas, agora, não com outros sujeitos, consigo.

\section{3 | O trabalho/emprego na escola como gerador de conflitos para os próprios professores}

O trabalho é uma das manifestações efetivas do humano. Sob o ponto de vista ontológico, é pelo trabalho que o ser humano se socializa e produz sua historicidade (LUKÁCS, 1979, p. 142). Por isso, a categoria trabalho expressa algo que é mais amplo e que, para Silva Júnior e Gonzalez (2001, p. 13), é assim caracterizado:

O trabalho funda o mundo dos homens [...] E o trabalho pode ser fundante de algo distinto de si próprio, porque, ontologicamente, pelas suas determinações mais imanentes, remete para além de si próprio. É esse "remeter para além de si próprio" que faz do trabalho uma categoria única do ser social, sua categoria fundante [...].

Ao trabalhar, os professores estão não somente se (auto)produzindo como seres históricos e sociais, mas agindo como trabalhadores e seres humanos. Ou seja, seu trabalho, que se tem defendido, é a produção da aula e, nela, a produção do conhecimento junto com outros sujeitos, além da participação em toda a dinâmica interativa da escola, de modo político e profissional, o que lhes confere um lugar de trabalhadores, podendo ser também fonte de satisfação:

Supomos que a busca de satisfação ocorra permanentemente na vida do indivíduo, da infância à velhice; assim, também nas relações de trabalho, onde o sujeito busca inserir-se no mundo cultural e conviver com outras pessoas torna-se lugar do encontro entre o desejo e a angústia. Isto é, a busca pela vivência de satisfação e o sofrimento. O sujeito em questão é o sujeito de desejo e sofrimento (BERTÃO; HASHIMOTO, 2006, p. 149).

Assim entendido, é no trabalho que o ser humano se faz valer, porque cria, em função de seu desejo e, ao mesmo tempo, diminui a angústia de permanecer no anonimato. Então, pode-se pensar o trabalho como a manifestação de um desejo e de uma necessidade, pois o que ele representa é a condição de cada sujeito, agora inserido em uma produção, em algo que o constitui por seu desejo, que passa a ser socializado. O trabalho é, então, o espaço e o tempo da produção e do estar exposto, inclusive a conflitos.

Interessante observar que, nas entrevistas com homens e mulheres professores, apenas cerca de dez por cento se referiram a si próprios como trabalhadores. As mulheres, em seus discursos, nas entrevistas, se apresentaram como missionadas, como vocacionadas. Explicaram sua opção por trabalhar como professoras devido à necessidade de realizar um trabalho social, pela influência da família e amigos, pela falta de oportunidades para se dedicar a outras profissões, pelas facilidades em se tornar professoras, uma vez que cursos de licenciatura são mais facilmente acessados no interior do Estado. Já os homens, em maior parte, afirmaram ter escolhido a profissão pela importância em trabalhar com educação, porém esclareceram que trabalhavam com componentes curriculares específicos e não nos Anos Iniciais do Ensino Fundamental, o que, no seu discurso, pareceu evidenciar um lugar social diferenciado. Tais evidências se reve- 
lam nos discursos elaborados para responder à questão sobre como escolheu a profissão: " $A h$, eu acho que além de uma profissão é um compromisso, um comprometimento meu, pessoal, que vai além do salário, além daquilo que a gente pode receber financeiramente, de material. Ser professor é, é uma missão, um comprometimento mesmo" (Professora Ângela) Ou a mesma pergunta respondida por um professor homem: "O trabalho do professor é tudo, é fundamental. É orientar, não como um conselheiro, orientar para os saberes, orientar como compreender o conteúdo. Mas, como eu disse, eu trabalho com os Anos Finais do Ensino Fundamental, é diferente" (Professor José).

Tais evidências comprovam que o trabalho representa, em muitas sociedades, como a brasileira, a possibilidade de os sujeitos se sentirem pertencendo e obtendo reconhecimento. Um trabalho que, nessa sociedade, por suas características capitalistas, acontece, na maior parte, por inserção em um emprego. E, sobretudo, nesses tempos, nos quais o desemprego é estrutural e aumenta substancialmente, estar incluído no mundo do trabalho parece significar ocupar um lugar de pertencimento, o que possibilita, aparentemente, condições de opinar, de participar, de ser cidadão, como afirma Organista (2006, p. 53): "[...] na sociedade regida pelo capital, não é o direito ao trabalho a fonte de cidadania; ao contrário é o emprego a sua condição."

Afirmou-se, antes, que o trabalho e o emprego, modos complementares de inclusão na sociedade capitalista, são formas de pertencer e produzir. Produzir e manter-se. É, deste modo, a relação mais direta dos sujeitos com sua condição de continuidade, tanto do ponto de vista da subsistência, quanto do ponto de vista cultural e histórico, pois, em meio às relações sociais de produção, os trabalhadores se constituem e passam a produzir suas concepções de mundo. Portanto, percebe-se que uma característica dimensionadora do ser humano é efetivamente o trabalho, base para que se produzam outras condições de vida.

Para fins de melhor explicitação, frisa-se que o trabalho e o emprego são diferentes. $O$ trabaIho está relacionado teleologicamente ao que é o ser humano, sua capacidade de intervir na natureza ou, se pode dizer, é um modo de viabilizar a condição de desejo, de buscar satisfação, de obter reconhecimento produzindo, ou melhor, reconhecimento no e pelo produto do trabalho: "[...] a forma específica de retribuição é o reconhecimento no sentido duplo do termo: reconhecimento no sentido de admitir essa contribuição da pessoa e reconhecimento no sentido de gratidão" (DEJOURS, 1999, p. 29). Há, nessa busca de reconhecimento, um duplo sentido: reconhecer-se como sujeito e tornar-se psiquicamente mais em condições de pertencer ao social. Implicam-se a objetividade do trabalho e a subjetividade do trabalhador. Quanto a esta implicação, Titoni afirma que, pelo trabalho, os sujeitos se reconhecem, se sentem realizados e se representam socialmente, "[...] produzindo, portanto, não só objetos, mas uma condição que é efetivamente sua. Por representar essa trajetória, o trabalho possui significado que perpassa a estrutura sócio-econômica, a cultura, as necessidades, os valores e a subjetividade daquele que trabalha" (TITONI, 1994, p. 12).

Ao mesmo tempo, e não como elemento antagônico, o emprego diz respeito à capacidade dos seres humanos de se manterem, sobreviverem em uma sociedade capitalista, de poderem consumir e de se constituírem cidadãos. Embora o empregado produza, o faz porque é demandado. Enquanto o trabalho existe antes e depois do emprego, estabelecendo a condição de o mundo humano existir, o emprego reproduz as relações sociais. Tal condição do emprego, em alguns casos, gera certa dubiedade. Nos discursos, durante as entrevistas realizadas, ao mesmo tempo em que os professores sabem ser fundamental receber um salário, também parecem querer fazer prevalecer um descolamento entre trabalho pedagógico e o fato de serem pagos por sua produção, reforçando o que, antes, se denominou vocação ou messianismo, aspectos presentes nos discursos: "O salário hoje... o professor é alguém que trabalha... a gente trabalha, a gente faz, a gente reclama, mas não é o salário que vai conduzir minha prática. Na minha função de ser professora, na minha ação, não olho e nem estou agindo pelo salário, porque se olhar, fico 
frustrada, triste. Nessas horas, então, me lembro que tenho uma vocação e penso somente nisso". (Professora Joceli)

A vocação é, no discurso, a condição para o trabalho. Entretanto, empregada a força de trabalho e, portanto, sujeita a exigências, acaba por ver seu ideal colonizado pela exigência. A vocação coaduna-se com o trabalho e não com o emprego. E a professora entrevistada explica seu ideal a partir das condições de emprego.

Ainda com referência ao salário, essa contrapartida pelo trabalho, com a qual os trabalhadores se mantêm, pode-se observar evidente descontentamento dos professores, mesmo que se esforcem para o melhor possível a despeito do parco salário na rede pública, como afirma uma das entrevistadas: "[...] o salário meu que sou contratada é péssimo. Tenho muito o que fazer, o tempo todo e, ainda assim, eu não consigo pagar as minhas contas. Vivo atordoada porque eu não tenho dinheiro, mas espero muito que vá melhorar um dia" (Professora Isabel). Subjacentemente, a Professora revela que se instaurou uma precarização das suas condições de trabalho, ao relacionar que o salário é deficiente, mas as atividades demandadas são muitas e a todo tempo. Trabalho precário é aquele em condições degradantes ou sem amparo legal, "[...] com a exploração do sobretrabalho, exercendo atividades remuneradas sem vínculo salarial direto, ou mesmo não remuneradas, bem como as diversas formas de trabalho em domicílio" (ORGANISTA, 2006, p. 43). Oliveira (2004, p. 1138), do mesmo modo, analisando o trabalho dos professores, destaca que a precarização está nas relações "[...] intrínsecas ao processo de trabalho, mas compreende principalmente as relações de emprego, apresentando uma tentativa de flexibilização e até mesmo desregulamentação das leis trabalhistas". Para exemplificar, também é possível lembrar as inúmeras horas-reunião, para além do horário, o compromisso com as atividades da escola nos finais de semana e a impossibilidade de planejar no tempo em que está na escola, gerando, desse modo, a intensificação. Intensificação, precarização e exploração, neste sentido, estão inter-relacionadas, sendo resultantes das condições relativas ao emprego que afetam o trabalho. É por essas condições de emprego que o trabalho se torna fonte de conflitos e mal-estares: "Tanto é que eu estava sendo professora até dois meses atrás. Não estava sendo uma professora muito feliz, pela turma que eu vinha assumindo, pela incidência que estava fora da sala de aula e eu não conseguia ficar bem. Pedi para sair de lá e, com isso, eu sabia que teria perdas. Mas mesmo assim eu mesma o pedi. Para poder me sentir mais feliz, menos exigida o tempo todo, porque não seria por oitocentos reais que eu ia vender minha felicidade né?" (Professora Tatiana).

Os conflitos evidenciados pelos trabalhadores apresentam-se quando os sujeitos despendem demasiadamente sua condição subjetiva para o trabalho, podendo ou não chegar, não raramente, à realização. Nesse processo, veem-se limitados pelo emprego, pois este lhes apresenta imperativos que restringem essa realização. Analisado o conjunto de discursos dos professores entrevistados, apesar desses quadros cotidianos na escola, apresenta-se, no ambiente de trabaIho, um processo de expressão otimista que visa a encontrar uma maneira de buscar incessantemente a satisfação, a despeito do mal-estar: "Eu acho que a gente deveria ir além das conversas... mas pelo menos eu acho que é um primeiro passo quando tu consegues falar, porque a gente sabe que a direção também é presa a outras coisas. Cada um tem umas amarras, umas coisas atreladas a outras que fica difícil. A gente é cobrada de alguma forma, mas também não vem retorno, então, às vezes, fica assim: muita conversa, tudo uma coisa muito maravilhosa, mas que, na realidade, não é bem assim" (Professora Jussara).

Pode-se imaginar o contexto resultante do fato de vários sujeitos, buscando modos de realização, negando o que Ihes é demandado pelo emprego. Tal situação vai se ampliando paulatinamente, na medida em que também atinge outros sujeitos da comunidade escolar: pais, estudantes. Torna-se um ciclo de queixas que se alimenta e se reforça, sem que se busquem as alterações próprias da condição de emprego, relegando ao trabalho todas as fontes de queixas. Não é o trabalho que gera o mal-estar, mas as condições nas quais está inserido o emprego. $\mathrm{E}$ 
essas, mais do que problema dos professores, constituem-se questões políticas ampliadas, implicadas no como a educação tem sido vista e patrocinada em âmbito de governo e de Estado. Em perspectiva semelhante, Esteve (1992, p. 81-82) afirma que "[...] a atitude mais frequente, dadas as atuais expectativas de emprego, é a de manter mais ou menos assumido o desejo de abandonar a profissão docente porém se chegar a um abandono real, recorrendo então a diferentes mecanismos de evasão dos problemas cotidianos". Nesse estado, os professores não conseguem produzir a partir da sua condição desejada em função das condições que o emprego desenha, e instaura-se um processo de mal-estar: "É meu trabalho. Ele é meio individualizado. O que eu percebo, quando há um aluno, por exemplo, um aluno meu que surta, eu não tenho com quem contar, porque falta pessoal dentro da escola. Foram mandadas muitas pessoas embora e agora a administração desse novo governo está nos deixando sem respaldo algum. A gente não tem mais ajudante, não tem mais auxiliar. Então, o coordenador de turno fica aqui quase louco, tentando nos ajudar, corre de um lado para outro". (Professora Soraia).

Quando os professores não encontram alternativas possíveis para superar esse quadro de mal-estar, instaura-se o sofrimento. A não resolução dos conflitos ou estar submetido a certo mal-estar gera sofrimento. Porém, vale o alerta: o trabalho não é somente sofrimento, porque se constitui na realização do desejo do sujeito (BERTÃO; HASHIMOTO, 2006, p. 148).

Na seção seguinte, incluir-se-á outro aspecto a ser analisado: as relações interpessoais no interior da escola, lugar e tempo do trabalho/emprego dos professores, como fontes de conflito.

\section{4 | As relações sociais com estudantes e demais professores como geradoras de conflitos}

A escola é um ambiente rico e diversificado de sociabilidades. Nela, há interações entre sujeitos com diferenciadas historicidades que passam a conviver em torno de um objetivo comum: produzir conhecimentos. Dada essa diversidade social, geram-se, obviamente, conflitos. No caso dos professores e estudantes, há diferença de historicidades, opiniões: "Professores e alunos dão valores diferentes à mesma ação e reagem diferentemente ao mesmo ato: isso é conflito" (CHRISPINO, 2007, p. 17). E, na escola, tudo parece necessitar ser igualado, normalizado: "Como a escola está acostumada historicamente a lidar com um tipo padrão de aluno, ela apresenta a regra e requer dos alunos enquadramento automático" (CHRISPINO, 2007, p. 17). $\mathrm{Na}$ escola, nessa perspectiva, não há espaço para a divergência, para a diferença de opinião: "Quanto mais diversificado for o perfil dos alunos (e dos professores), maior será a possibilidade de conflito ou de diferença de opinião. E isso numa comunidade que está treinada para inibir o conflito, pois este é visto como algo ruim, uma anomalia do controle social" (CHRISPINO, 2007, p. 17).

Entre a manifestação e a inibição, os conflitos, de algum modo, se manifestam. Esse é o espaço da educação, seja na escola ou nos espaços sociais ampliados. Um possível entendimento sobre educação é apresentado por Jerusalinsky (1995, p. 19) ao afirmar ser um processo que "[...] não opera por um saber instintivo mas por um saber social; simboliza e demanda - dando seu lugar ao pai - alterizando o sujeito de um modo arbitrário e radical, lhe impondo ideais que o arrastam muito longe do paraíso materno". Reitera-se ser assim também na educação escolar, porque os sujeitos ali convivem, há expectativas, há desejos, portanto, há conflitos.

Ao chegar à escola, os professores investem expectativas no trabalho e nos sujeitos com quem trabalharão. Do seu ponto de vista, é natural. Buscam, então, atender essas expectativas e serem reconhecidos. O reconhecimento é um modo de atender ao desejo: "O reconhecimento é, portanto, o ato de confrontação de duas autoconsciências no processo de se tornarem propriamente humanas. Elas se reconhecem, para si mesmas e para a outra, ao transformarem em verdade objetiva o que era uma simples certeza subjetiva" (GARCIA-ROZA, 1991, p. 143). 
Sabe-se que é no trabalho e na educação que o sujeito investe seu desejo, ilustrado através de sua manifestação e representado pelos comportamentos que o singularizam. É o que vai dar sustentação no trabalho e, consequentemente, reconhecimento do lugar que é ocupado pelo sujeito. Sendo assim, é necessário considerar a ação inconsciente implicada na determinação do trabalho, pois não é uma simples escolha consciente que permitiria pensar na possibilidade de optar entre várias alternativas. Entretanto, na escola, há outros sujeitos, outras subjetividades. Aos professores, imersos nesse campo de subjetividades, cabe um trabalho, o que implica em se relacionar com outros sujeitos. Tal diversidade é relatada nos discursos das professoras entrevistadas, como nos casos a seguir, destacando a ineficácia das reuniões de planejamento na escola e a falta de acolhimento às suas demandas: "Porque é muito fácil eu chegar aqui e dizer que é tudo muito lindo e maravilhoso, mas quando vou para minha sala de aula, às vezes, me sinto sozinha e não tenho a quem recorrer. A gente fica perdida e não sabe aonde vai... se chateia também com todo um sistema que não funciona. Na verdade, a gente é morta assim pelo cansaço" (Professora Tamara).

E, em outro discurso, encontra-se uma narrativa semelhante: "Tu não tens com quem contar. A escola não se envolve com meu trabalho. E eu raramente consigo passar para a escola o que é o meu trabalho, porque não tem esse espaço de tempo para a gente trocar ideias" (Professora Sofia).

A análise desses conflitos pode acontecer, em uma abordagem profissional, considerando o fato de a escola estar inclusa em uma sociedade capitalista, na qual se produzem conflitos de classe, sociais e profissionais, isolados ou imbricadamente. Ou, em uma análise subjetiva, complementar à anterior, em que se entende que os conflitos podem acontecer a partir da diferença entre as subjetividades e a cultura escolar.

Optou-se por considerar em relevo os conflitos de origem profissional dentro da escola, conforme Saes e Alves (2003, p. 12), que os denominam "conflitos funcionais", e os explicam como sendo indicativos de conflitos de grupos "[...] alocados em situações diferenciadas, porém complementares dentro da instituição escolar", incluindo os gestores (professores, comunidade, estudantes). Nessa situação social, "[...] a eclosão e desenvolvimento do conflito não levam à destruição do modelo vigente de instituição escolar, e sim à evolução, sem ruptura, do seu modo de funcionamento" (SAES; ALVES, 2003, p. 12). Na sua condição profissional, os professores são trabalhadores, principalmente, dentro da escola, onde produzem prioritariamente a aula, que é um trabalho diferenciado, causando uma separação entre os sujeitos da aula e das atividades além da aula. Um entendimento assim da escola gera a percepção de que, se há hierarquias, há interesses e poderes que as normatizam, se tornam cotidianas e até naturalizam sem, necessariamente, serem objetos de reflexão e acontecem através de mecanismos disciplinares cuja base são medidas que visam a controlar de modo a tornar dócil e, deste modo, suportar. Há uma tensão contínua produzida na diferença e no seu controle. Nesse processo, os professores parecem imaginar que lhes cabe a manutenção, a todo custo, da ordem, impedindo, não raro, as interações naturais, o que resulta em contínuo embate entre professores e estudantes, cada um com um objetivo a atingir em prol de se sentir bem na aula.

Portanto, há certa origem difusa dos conflitos: tanto podem surgir dentro como fora da escola, mas acabam, inexoravelmente, refletindo-se no trabalho pedagógico escolar dos professores. Para Saes e Alves (2003, p. 23), no caso dos professores, esse conflito profissional acirrado revela-se sob a forma de conflitos sociais mais amplos:

[...] os professores, revoltados com os baixos salários, com a desvalorização social da atividade docente e com a proletarização do trabalho do ensino, tendem a resistir a essa situação através do método proletário clássico da sabotagem às suas próprias atividades profissionais [...]. 
Organiza-se, então, uma série de decorrências nos demais sujeitos da escola, cada qual defendendo seu lugar social, criando-se um conflito generalizado, cuja gênese está em um processo no qual "[...] articulam-se, na prática professoral, o protesto social e a revolta docente contra a incidência dos procedimentos do burocratismo no domínio tecno-pedagógico (SAES; ALVES, 2003, p. 23). Por isso, se pode afirmar que a escola, organizada sob o modelo de distribuição de funções, busca reproduzir relações sociais presentes também em outras instituições sociais, conforme caracteriza Aquino (1998, p. 8), gerando um trabalho escolar "[...] marcado por uma espécie de 'reprodução' difusa dos efeitos oriundos de outros contextos institucionais molares (a política, a economia, a família, a mídia, etc)".

Na escola, portanto, na perspectiva sociológica e, aqui, da profissão; e sob a perspectiva psicológica, são encontrados conflitos que afetam, inevitavelmente, os professores. Esses conflitos referem-se a dinâmicas subjetivas diferenciadas e podem ser entendidos, a partir da perspectiva de Chrispino (2007), da seguinte maneira: conflitos provocados pela "pluralidade de pertencimento", no caso de os professores trabalharem em mais de uma escola ou mesmo em sistemas escolares diferenciados (particular e público, por exemplo); conflitos oriundos da participação na elaboração do projeto institucional, na medida em que este projeto faz aflorar as diferenças de crenças e concepções; conflitos surgidos pela necessidade de trabalhar em conjunto na implementação do projeto pedagógico; conflitos entre gestores: "quando não há coincidência entre a figura da autoridade formal (diretor) e da autoridade funcional (líder situacional)" (CHRISPINO, 2007, p. 19). Acrescenta-se, ainda, outro conflito a essa citação, que, embora presente nos demais, precisa ser destacado por ser, talvez, o que mais provoca decorrências: o que se estabelece na relação necessária à produção do conhecimento entre professores, que assumem esse lugar de função paterna, e dos estudantes, que testam essa função. Parece ser o que mais afeta os professores, na medida em que põe em teste o seu trabalho, as suas crenças pedagógicas e, sobretudo, o seu modo de interagir. Além disso, por ser o tipo de conflito vivido, normalmente, em público, envolvendo grupos de pessoas, intensifica-se. Arroyo (2004, p. 37). explica essa intensidade: "As condutas dos alunos põem em entredito nossos poderes e saberes, nossas auto-imagens doentes. $\mathrm{E}$, de maneira radical. Na raiz. Há motivos para perplexidades. Na nova relação com os alunos fica instalada uma nova relação, com nós mesmos".

Em meio aos conflitos, há, mas nem sempre, a possibilidade de escolher, entre tantas variáveis, agir de modo a colonizar, tolerar, demonizar, compreender os outros, romper ou aproximar mais. Através da linguagem, pode-se passar a agir, acirrando ou mesmo abrandando. Concorrem para tanto fatores inconscientes aliados aos lugares que cada um desenha para si. Obviamente, ideal seria poder compreender os demais, mas isso não depende de cada um, também Ihe é demandado. A compreensão implica uma série de outras condições subjetivas nem sempre possíveis. Vislumbram-se essas condições no que afirma uma professora: "Os estudantes são muito assim de contar, querem contar tudo o que acontece com eles em casa, na rua, vindo para a escola. Então, muitas vezes, a gente tem que dar essa atenção para o aluno. Parar um pouco a aula que a gente está trabalhando para ouvir o aluno, dar oportunidade para ele poder falar, também, não passar por cima disso, do que está acontecendo com ele, eu acho que é isso. Nem sempre posso, porque não se pode atrasar o trabalho, a coordenadora, a escola exigem cumprimento dos tempos" (Professora Rosa).

Para alguns, os conflitos entre os sujeitos, de características dialógicas, carrega um sentido pejorativo, como algo que devesse ser evitado a qualquer custo. No entanto, Chauí (1980, p. 156) destaca que a divergência é natural em uma sociedade marcada pela diversidade e "[...] o que a sociedade deve fazer com o conflito é trabalhá-lo, possibilitando a discussão e o confronto [...] é assim que a história se faz, nessa aventura em que o cidadão se lança em busca do possível".

Dia a dia, essas relações interpessoais se sucedem, acirrando-se ou arrefecendo. Interessante notar que podem ser apenas manifesto de um conteúdo latente: o conflito em si, ou seja, como 
se o próprio conflito organizasse essas relações. Importante diferenciar os conflitos necessários e integrantes do trabalho pedagógico, ligados aos movimentos naturais da profissão e os conflitos reveladores de doenças sociais responsáveis por dificultar o trabalho e a convivência. Estes parecem estar relacionados mais à negação da condição de sujeito pela situação de emprego e, com isso, a negação de sua condição como sujeito do conflito, instaurando-se um mal-estar que assola o grupo.

\section{5 | Considerações finais}

A escola é uma das instituições sociais imersas na sociedade capitalista. É de se imaginar que seja um palco de conflitos, ainda que, muitas vezes, sejam mascarados, naturalizados para evidenciar uma aparente harmonia do ambiente. Alimenta-se essa aparência com mitos que vão se tornando discursos, tais como declarar que conflitos sejam prejudiciais ao trabalho pedagógico ou que possam, de alguma forma, impedir que se realize o Projeto Pedagógico da escola. Contrariamente, os conflitos dialógicos são saudáveis, desde que não coloquem os sujeitos em sofrimento contínuo. Nessa perspectiva, não se deve ignorá-los, mas entendê-los, pô-los em discussão, fazendo a palavra circular de algum modo, pois essa é a garantia de uma espécie de manutenção de algo que se poderia denominar "saúde social e socializadora" da escola.

Somente assim haverá possibilidades de a escola não adoecer, tornar-se, quem sabe, favorável aos sujeitos, porque nela haverá condições para a palavra circular. A prática da linguagem é ainda um dos melhores modos de constituir a saúde da instituição. Por esses motivos, destaca-se que aceitar as condições em que e como se produzem os conflitos é manter o diálogo em contínuo. As diferenças e diversidades são salutares na expressão de pensamentos, projetos, crenças e propostas de trabalho. Possibilitam que os professores se reconheçam como trabalhadores que pertencem à instituição, como sujeitos, fazendo de sua palavra um meio de produção de sentidos a partir dos conflitos. Desse modo, poder-se-ia superar a aparente dicotomia entre o trabalho dos professores e a evidência de conflitos cotidianos na escola: pela não negação, pela dialogicidade, pelo enfrentamento coletivo, pela dissensão até... mas não pela omissão e pelo ocultamento do que é, no espaço social, uma possibilidade a ser considerada: a evidência de diferenças, dilemas e conflitos. 


\section{Referências}

ANTUNES, R. Reestruturação produtiva e o mundo do trabalho. In: SENNA, E. (Org.). Trabalho, educação e política pública. Campo Grande: Ed. UFMS, 2003. p.13-50.

AQUINO, J. G. A violência escolar e a crise da autoridade docente. In: CEDES, Campinas, v. 19, n. 47, dez. 1998.

ARROYO, M. Imagens quebradas: trajetórias e tempos de alunos e mestres. Petrópolis, RJ: Vozes, 2004.

BERTÃO, F. R. B. M; HASHIMOTO, F. Entre o desejo e o sofrimento psíquico no trabalho: um estudo de caso com professora de educação infantil. Psicologia em Revista, Belo Horizonte, v. 12, n. 20, p. 141-163, dez. 2006.

CAETANO, A. P. Dilemas dos professores. In: ESTRELA, M. T. (Org.). Viver e construir a profissão docente. Porto: Porto Editora, 1997.

CHAUI, M. O que é ideologia. São Paulo: Brasiliense, 1980.

CHRISPINO, A. Gestão do conflito escolar: da classificação dos conflitos aos modelos de mediação. Ensaio: Avaliação e Políticas Públicas em Educação, Rio de Janeiro, v. 15, n. 54, jan./mar. 2007.

DEJOURS, C. Conferências brasileiras. São Paulo: Fundap e Eaesp-FGV, 1999.

ESTEVE, J. M. O mal-estar docente. Lisboa: Escher/Fim de Século Edições. 1992.

FERREIRA, L. S. Gestão do pedagógico: de qual pedagógico se fala? Currículo sem Fronteiras, v. 8, n. 2, p. 176-189, jul./dez. 2008.

GALVÃO. I. Cenas do cotidiano escolar: conflito sim, violência não. Petrópolis: Vozes, 2004.

GARCIA-ROZA, L. A. Freud e o inconsciente. 2.ed., RJ: Zahar, 1991.
JERUSALINSKY, A. Apesar de você, amanhã há de ser outro dia - Dialética da demanda e do desejo na educação. In: (Org.). Educa-se uma criança? Porto Alegre: Artes e Ofícios, 1995.

LACAN, J. Seminário 2: O eu na teoria de Freud e na técnica da psicanálise. Rio de Janeiro: Zahar, 1985.

LUKÁCS, G. Ontologia do ser social: os princípios ontológicos fundamentais de Marx. São Paulo: Ciências Humanas, 1979.

OLIVEIRA, D. A. A reestruturação do trabalho docente: precarização e flexibilização. Educação e Sociedade, v. 25, n. 89, p. 1127-1144, set./dez. 2004.

ORGANISTA, J. H. C. O debate sobre a centralidade do trabalho. São Paulo: Ed. Expressão Popular, 2006.

PIMENTA, S. G. (Org.). Saberes pedagógicos e prática docente. In: _. Formação de professores: identidade e saberes da docência. São Paulo: Cortez, 1999.

SAES, D. A. M; ALVES, M. L. Uma contribuição teórica à análise de conflitos funcionais em instituições escolares da sociedade capitalista. In: RBPAE, v. 19, n. 1, p. 11-24, jan./ jun. 2003.

SÁNCHEZ VÁZQUEZ, A. Filosofia da práxis. 2.ed. Rio de Janeiro: Paz e Terra, 1977.

SARTRE, J. Crítica da razão dialética. Rio de Janeiro: DP\&A, 2002. tomo I

SILVA JÚNIOR, J.R.; GONZÁLEZ, J.L.C. Formação e trabalho: uma abordagem ontológica da sociabilidade. São Paulo: Xamã, 2001.

TITTONI, J. Subjetividade e trabalho: a experiência no trabalho e sua expressão na vida do trabalhador fora da fábrica. Porto Alegre: Ortiz,1994. 